\title{
Early life growth hormone treatment shortens longevity and decreases cellular stress resistance in long-lived mutant mice
}

\author{
Jacob A. Panici, ${ }^{*}$ James M. Harper, ${ }^{\dagger}$ Richard A. Miller, ${ }^{\dagger, \ddagger}$ Andrzej Bartke, ${ }^{*}$ \\ Adam Spong,* and Michal M. Masternak*,§,1 \\ *Department of Internal Medicine, Geriatrics Research, Southern Illinois University School of \\ Medicine, Springfield, Illinois, USA; ${ }^{\dagger}$ Department of Pathology and Geriatrics Center, University of \\ Michigan, Ann Arbor, Michigan,USA; ${ }^{\ddagger}$ Ann Arbor Veterans Affairs Medical Center Geriatrics

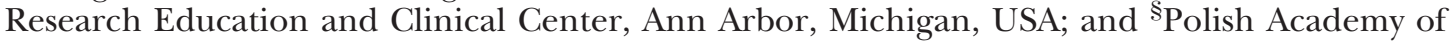 \\ Sciences, Institute of Human Genetics, Poznan, Poland
}

ABSTRACT Hypopituitary Ames dwarf mice were injected either with growth hormone $(\mathrm{GH})$ or thyroxine for a 6-wk period to see whether this intervention would reverse their long life span or the resistance of their cells to lethal stresses. Ames dwarf mice survived $987 \pm 24 \mathrm{~d}$ (median), longer than nonmutant control mice $(664 \pm 48)$, but GH-injected dwarf mice did not differ from controls $(707 \pm 9)$. Fibroblast cells from Ames dwarf mice were more resistant to cadmium than cells from nonmutant controls $\left(\mathbf{L D}_{50}\right.$ values of $9.98 \pm 1.7$ and $3.9 \pm 0.8$, respectively), but GH injections into Ames dwarf mice restored the normal level of cadmium resistance $\left(\mathrm{LD}_{50}=5.8 \pm 0.9\right)$. Similar restoration of normal resistance was observed for fibroblasts exposed to paraquat, methyl methanesulfonate, and rotenone $(P<0.05$ in each case for contrast of GH-treated $v$ s. untreated dwarf mice; $\boldsymbol{P}<0.05$ for dwarf $v s$. nonmutant control mice.) T4 injections into Ames dwarf mice, in contrast, did not restore normal life span. We conclude that the remarkable life-span extension of Ames dwarf mice, and the stress resistance of cells from these mice, depends on low levels of GH exposure in juvenile and very young adult mice.-Panici, J. A., Harper, J. M., Miller, R. A., Bartke, A., Spong, A., Masternak, M. M. Early life growth hormone treatment shortens longevity and decreases cellular stress resistance in long-lived mutant mice. FASEB J. 24, 5073-5079 (2010). www.fasebj.org

Key Words: Ames dwarf • aging • stress resistance

STUdies OF AGING IN LABORATORY animals have indicated that alteration of signaling pathways triggered by growth hormone $(\mathrm{GH})$, insulin, and insulin like growth factor-1 (IGF-1) can have a major effect on life span and aging in multiple species (1). In rodents, growth hormone deficiency or resistance is known to be associated with extended longevity of Snell dwarf, Ames dwarf, and GHRKO mice (2-6). On the other hand, there is some evidence to suggest that $\mathrm{GH}$ administration may be beneficial to the health of elderly people (7), although the literature on this point is equivocal (810). Meta analysis by Liu et al. led them to conclude that based on available evidence, GH cannot be recommended for use for healthy elderly individuals (11). Nonetheless, GH is widely advertised as an antiaging treatment.

The present study employed Ames dwarf (df/df) mice, which are $\mathrm{GH}$ deficient due to their homozygosity for a recessive loss-of-function mutation at the Prop1 locus (Prop1 ${ }^{\mathrm{df}}$ ) and resultant failure of differentiation of several lineages of anterior pituitary cells during fetal development (4). Besides GH deficiency, this mutation also leads to deficiency of prolactin (PRL) and thyroidstimulating hormone (TSH) production, with secondary suppression of circulating levels of insulin-like growth factor-1 (IGF-1), thyroid hormones, insulin, and glucose $(4,12-14)$. Ames dwarf mice live $\sim 50 \%$ longer than their normal siblings $(2,4)$. This mutation not only extends average and maximum longevity in these animals, but also leads to better maintenance of cognitive function (15), greater resistance to oxidative stress (16), and decreased or delayed incidence of cancer (17). Ames dwarf mice are characterized by increased insulin sensitivity $(13,18,19)$ along with decreased levels of serum glucose and insulin. Improved insulin signaling has been correlated with increased longevity, while insulin resistance often predicts shorter life span (19). Our previous studies with GH or GH/thyroxine (T4) treatment in Ames dwarf mice indicated that replacement of these hormones can negatively affect insulin signaling pathways, causing insulin resistance

\footnotetext{
${ }^{1}$ Correspondence: School of Medicine, Department of Internal Medicine, Division of Geriatric Medicine, $801 \mathrm{~N}$. Rutledge, Rm. 4389, P.O. Box 19628, Springfield, IL 627949628, USA. E-mail: mmasternak@siumed.edu

doi: $10.1096 /$ fj.10-163253

This article includes supplemental data. Please visit http:// www.fasebj.org to obtain this information.
} 
and several alterations in insulin signaling pathways in insulin target organs $(20,21)$.

In the present study we investigated the effects of early life treatment with GH on mouse longevity and on resistance of cultured dermal fibroblasts to different environmental stressors in $\mathrm{df} / \mathrm{df}$ mice. The results indicate that a relatively brief period of GH treatment during early stages of postnatal life can both shorten life span and decrease the resistance of skin-derived cell lines to stressful stimuli.

\section{MATERIALS AND METHODS}

\section{Animals}

Ames dwarfs (Prop ${ }^{\mathrm{df}}$ ), homozygous mice (df/df) were produced by mating heterozygous females and homozygous mutant males in our breeding colony at Southern Illinois University (SIU). In this colony, the Prop $1^{\mathrm{df}}$ mutation is maintained on a heterogeneous genetic background. All animal protocols were approved by the Southern Illinois University Laboratory Animal Care Committee. Animals were maintained under temperature- and light-controlled conditions $\left(20-23^{\circ} \mathrm{C}, 12-\mathrm{h}\right.$ light-dark cycle).

\section{Hormonal treatment}

\section{Growth hormone treatment and longevity}

Once-daily injection. Groups of 15-17 Ames dwarf males were subjected to treatment with porcine $\mathrm{GH}$ (pGH) via subcutaneous (s.c.) injection $[4 \mu \mathrm{g} / \mathrm{g}$ body weight $(\mathrm{bw}) / \mathrm{d}]$, given $1 \times / \mathrm{d}$ starting at the age of $2 \mathrm{wk}$ and continuing for $6 \mathrm{wk}$ (df/df-pGH treated). Once-daily saline-treated dwarfs (df/df) of the same age were used as a control. After 6 wk of treatment, animals were set aside for a longevity study, and mice in these groups were not exposed to any other manipulations except for recording of body weight.

Twice-daily injections. Groups of 9-10 Ames dwarf males were subjected to treatment with bovine $\mathrm{GH}$ (bGH) via s.c. injection $(6 \mu \mathrm{g} / \mathrm{g}$ bw/d), given $2 \times / \mathrm{d}$ starting at the age of 2 wk and continuing for $6 \mathrm{wk}$ (df/df-bGH treated). On Saturdays and Sundays, animals were injected only once with a full dosage following a previous protocol (21). Untreated $\mathrm{df} / \mathrm{df}$ and wild-type (WT) littermates of the same age were used as a control. After $6 \mathrm{wk}$ of treatment, some animals were set aside for a longevity study, and mice in these groups were not exposed to any other manipulations except for recording of body weight.

Separate groups of animals produced using the same protocol were evaluated for glucose tolerance at 2 time points: $1 \mathrm{~d}$ after last injection and 1 mo after last injection, using a previously published protocol (21).

\section{Thyroxine treatment and longevity}

Female and male Ames dwarf mice were treated with T4 (L-thyroxine; Sigma, St. Louis, MO, USA) in $0.9 \%$ saline solution at $\mathrm{pH} 7.8$ by s.c. injection $(0.1 \mu \mathrm{g} / \mathrm{g}$ bw; $0.7 \mu \mathrm{g} / 50 \mu \mathrm{l}$ dose) $3 \times /$ wk (Monday, Wednesday, Friday), following a previously published protocol (20). Control Ames dwarfs were injected with $0.9 \%$ saline according to the same schedule. Each group consisted of 10 or 11 mice. All treatments were started at the age of $2 \mathrm{wk}$ and continued for $6 \mathrm{wk}$. At the age of $8 \mathrm{wk}$, the treatment was stopped, and longevity was monitored.

\section{Growth hormone treatment and fibroblast stress resistance}

Groups of 12-14 Ames dwarf males were given $2 \times / d$ s.c. injections of pGH (6 $\mu \mathrm{g} / \mathrm{g}$ bw/d; Alpharma, Bridgewater, NJ, USA), starting at the age of $2 \mathrm{wk}$ and continuing for $6 \mathrm{wk}$ (df/df-pGH treated). On Saturdays and Sundays animals, were injected only $1 \times$, with a full daily dosage $(6 \mu \mathrm{g} / \mathrm{g}$ bw/d). Untreated $\mathrm{df} / \mathrm{df}$ and normal $(\mathrm{N})$ littermates of the same age were used as controls. After 6 wk of GH treatment, the animals were deprived of food overnight; a serum sample was taken for blood glucose determination, and mice were then euthanized (21). Tails were collected, surface-sterilized using $70 \%$ ethanol, placed in sterile culture medium, and shipped by overnight courier to Michigan for establishment of cell cultures.

\section{Fibroblast stress study}

Primary cultures of dermal fibroblasts were derived from each tail snip using an established protocol (22-24). In brief, on arrival biopsies were further washed in $70 \%$ ethanol, placed in Dulbecco's modified Eagle medium (DMEM, high-glucose variant), diced to $<0.5 \mathrm{~mm}$, and digested overnight with collagenase type II (1000 U total/biopsy) dissolved in DMEM supplemented with $10 \%$ heat-inactivated fetal bovine serum, antibiotics $(100 \mathrm{U} / \mathrm{ml}$ penicillin and $100 \mu \mathrm{g} / \mathrm{ml}$ streptomycin), and $0.25 \mu \mathrm{g} / \mathrm{ml}$ of fungizone at $37^{\circ}$ in a humidified incubator with $5 \% \mathrm{CO}_{2}$ in air. After collagenase treatment, cells were dislodged, passed through sterilized nylon netting, and centrifuged for $5 \mathrm{~min}$ at $200 \mathrm{~g}$ to pellet the cells. After centrifugation the cells were resuspended in DMEM with $20 \%$ heat-inactivated fetal bovine serum, antibiotics and fungizone as indicated previously. Approximately $2.5 \times 10^{5}$ cells in $5 \mathrm{ml}$ medium were seeded into tissue culture flasks of $25 \mathrm{~cm}^{2}$ surface area. Cell cultures were then fed at d 3 (replacing two-thirds of the medium), and subcultured at $\mathrm{d} 7$ at a density of $7.5 \times 10^{5}$ in tissue culture flasks of $75 \mathrm{~cm}^{2}$ surface area to produce passage 1 cultures. Subsequent passages were split at 6 -d intervals, with $\sim 2 / 3$ total volume of media removed at $d$ 3 and replaced with fresh DMEM with $20 \%$ heat-inactivated fetal bovine serum with antibiotics and fungizone. At the end of the third passage ( $6 \mathrm{~d}$ after seeding), confluent cells were harvested for assessment of stress resistance as described previously (22-24). In brief, cells were counted by hemocytometer, diluted to a concentration of $3 \times 10^{5} / \mathrm{ml}$ in DMEM with $10 \%$ fetal bovine serum with antibiotics and fungizone, and seeded into a 96-well tissue culture-treated microtiter plate at a volume of $100 \mu \mathrm{l} /$ well. The next day, the medium was removed and replaced by serum-free DMEM supplemented with $2 \%$ bovine serum albumin, antibiotics, and fungizone for $\sim 24 \mathrm{~h}$, followed by exposure to the cytotoxic stressors over a range of doses. For UV light testing, cells were washed, then irradiated with UV light $(254 \mathrm{~nm}$ at 5.625 $\mathrm{J} / \mathrm{m}^{2} / \mathrm{s}$ ) in $100 \mu \mathrm{l}$ of Dulbecco's PBS. Survival was measured $18 \mathrm{~h}$ later by a test based on reductive cleavage of the tetrazolium dye WST-1 using the manufacturer's protocol. The $\mathrm{LD}_{50}$, i.e., dose of stress agent needed to kill $50 \%$ of the cells, was then estimated for each cell line for each stress.

\section{Statistics}

The effect of GH treatment on fibroblast stress resistance was evaluated, based on $\mathrm{LD}_{50}$ estimates, using 1-way ANOVA followed by a Tukey-Kramer post hoc test in instances where the ANOVA calculation indicated a significant difference 


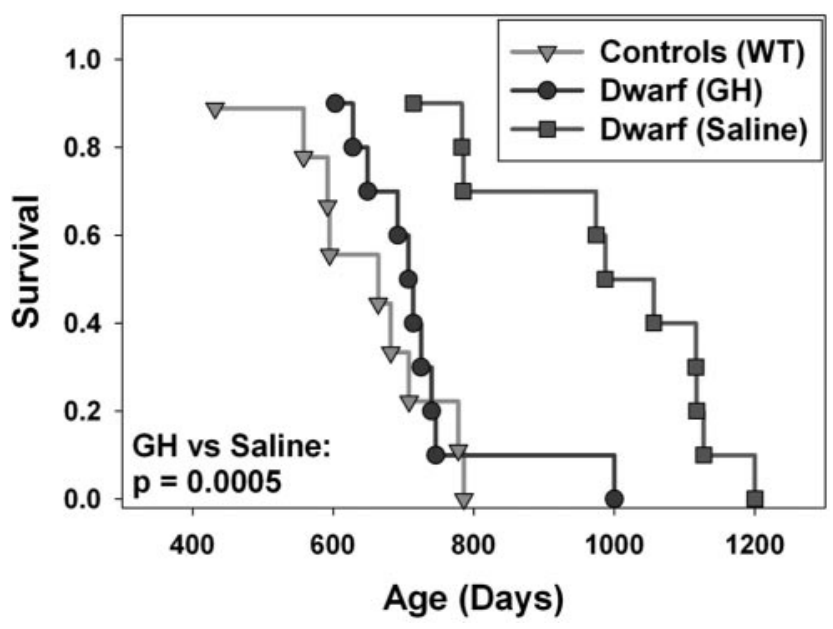

Figure 1. Kaplan-Meier survival plot of Ames dwarf mice treated with bGH [dwarf $(\mathrm{GH})]$, untreated WT controls, and untreated Ames dwarf mice [dwarf (saline)] $(n=9-10)$. All mice were males treated $2 \times / \mathrm{d}$ for $6 \mathrm{wk}$ starting at age $2 \mathrm{wk}$ via s.c. injection $(6 \mu \mathrm{g} / \mathrm{g}$ bw/d).

among treatment groups. In cases where the normality assumption was violated, data were $\log$ transformed prior to analysis. Differences in mouse survival were evaluated using the log-rank test.

\section{RESULTS}

\section{Hormonal treatment and longevity}

Once-daily GH treatment with the dosage of $4 \mu \mathrm{g} / \mathrm{g}$ $\mathrm{bw} / \mathrm{d}$ starting at $2 \mathrm{wk}$ of age and continuing for $6 \mathrm{wk}$ did not alter the longevity of Ames dwarf mice (Supplemental Fig. 1). In contrast, $\mathrm{GH}$ administered $2 \times / \mathrm{d}$ to $\mathrm{df} / \mathrm{df}$ mice between 2 and 8 wk of age at a higher dose of 6 $\mu \mathrm{g} / \mathrm{g}$ bw/d significantly shortened their life span relative to untreated df-df mice (log-rank test, $P<0.0005$ ) (Fig. 1). The longevity of these GH-treated $\mathrm{df} / \mathrm{df}$ mice was indistinguishable from the life span of the WT littermate controls.

As expected, GH treatment caused significant somatic growth of $\mathrm{df} / \mathrm{df}$ mice in comparison to their untreated littermates $(P<0.001)$; however, the GHtreated dwarf mice did not reach the same body weight as the WT controls (Fig. 2).

A glucose tolerance test (GTT) performed $1 \mathrm{~d}$ after the last injection of $\mathrm{GH}$ indicated that $\mathrm{GH}$ treatment resulted in significant impairment of glucose tolerance in $\mathrm{df} / \mathrm{df}-\mathrm{bGH}$ mice in comparison to $\mathrm{df} / \mathrm{df}$ mice $(P<0.01)$ (Fig. 3A). This effect was transient, in that glucose tolerance was no longer different between bGH-treated df/df and untreated df/df mice 1 mo after the cessation of the treatment (Fig. 3B).

$\mathrm{T} 4$ levels are also severely reduced in $\mathrm{df} / \mathrm{df}$ mice. Injections of T4 between 2 and 8 wk of age did not significantly alter longevity of either males or females $(P=0.3$ and $P=0.5$, respectively) (Fig. 4), although body weight was increased by this treatment in both sexes $(P<0.0001$ for both) (Fig. 5).

\section{Growth hormone treatment and fibroblast stress resistance}

Effective responses and protection from negative effects of environmental and cellular stressors may play an important role in determining longevity and in protection from age-related diseases. As expected from previous studies in Ames dwarf mice and in phenotypically similar Snell dwarf mice (22-24), dermal fibroblasts derived from untreated Ames dwarf mice were significantly more resistant than cells from littermate controls to the lethal effects of cadmium, paraquat, and MMS as well as resistant to rotenone-induced inhibition of the plasma membrane redox system (PMRS) (25, 26), as shown in Fig. 6. For each of these agents, resistance is significantly higher in cells from untreated $\mathrm{df} / \mathrm{df}$ mice than in cells from littermate controls, as evaluated by 1-way ANOVA followed by the TukeyKramer post hoc test $(P<0.04$ for all). Cells from Ames dwarf mice were also better able to tolerate low glucose culture conditions in comparison to cells derived from WT mice, although this difference was only marginally significant by ANOVA $(P=0.06)$ (Fig. 6). Although a previous study had found increased resistance of Amesderived fibroblasts to hydrogen peroxide and UV irradiation (24), in the current group of mice we found no significant difference between dwarf and controls in resistance to these two agents (data not shown).

Cells from dwarf mice that had been exposed to $6 \mathrm{wk}$ of $\mathrm{GH}$ treatment resembled cells derived from normal control mice in their lower resistance to MMS, paraquat, and cadmium toxicity, as well as their tolerance to low glucose culture conditions ( $P \leq 0.05$ for all) (Fig. 6$)$. Resistance of cells from GH-treated dwarf mice to rotenone-induced inhibition of PMRS activity was not

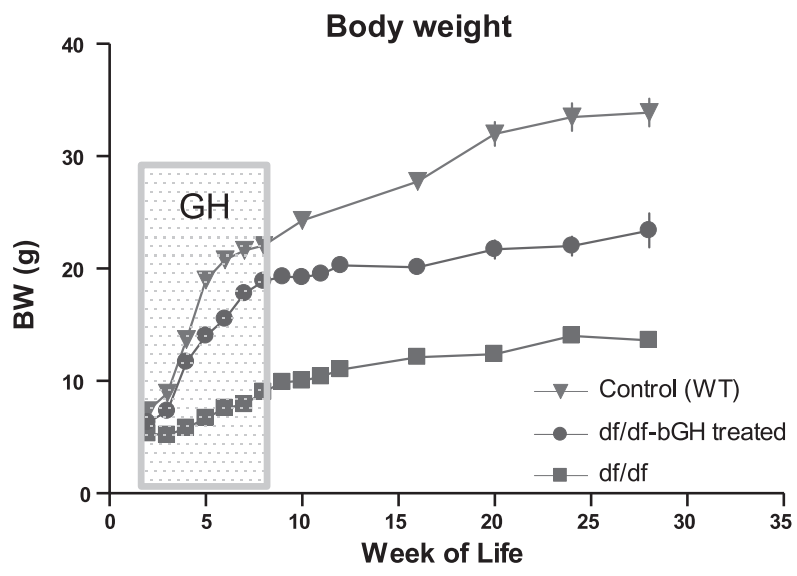

Figure 2. Body weight of Ames dwarf and control WT male mice subjected to $6 \mathrm{wk}$ of $\mathrm{GH}$ treatment. Ames dwarf (df) mice were exposed between 2 and 8 wk of age (as indicated) with bGH (df/df-bGH treated, $n=22)$. Untreated WT $(n=9)$ and $\mathrm{df} / \mathrm{df}(n=17)$ were used as controls. Time points represent mean \pm SE weight of each group. 


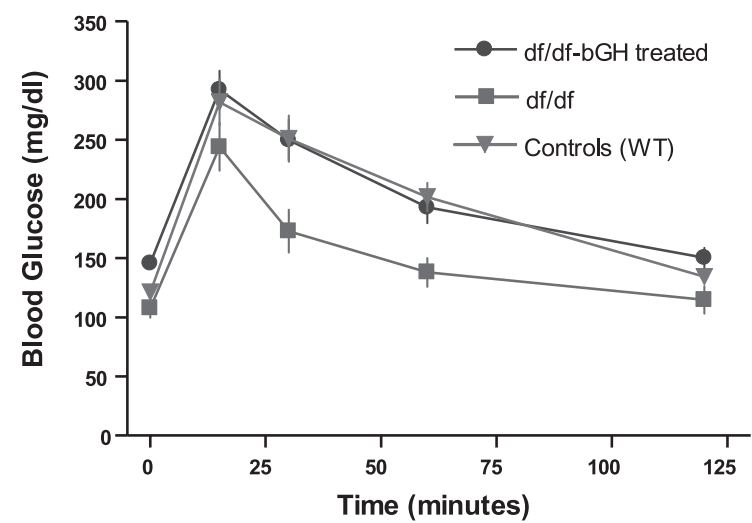

B

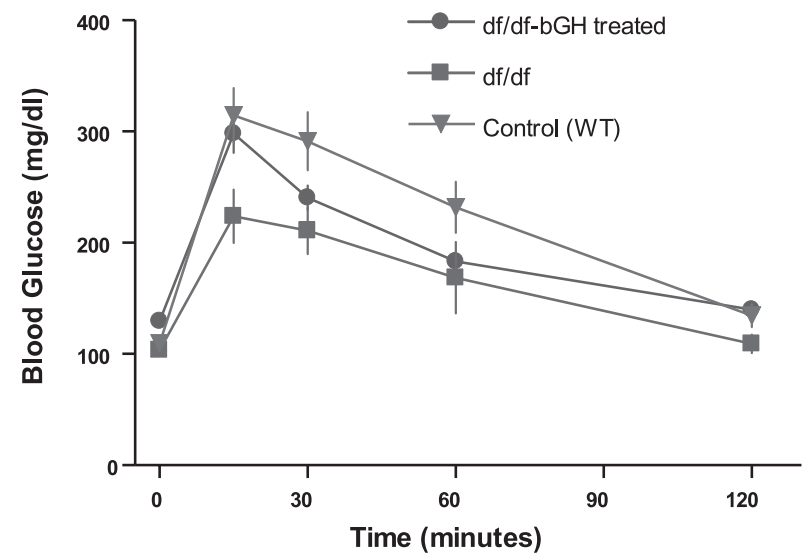

Figure 3. Results of GTTs in GH-treated Ames dwarf (df/df-bGH treated) and untreated WT and df/df mice. All groups were deprived of food overnight. In the morning, mice were injected i.p. with glucose $(2 \mathrm{~g} / \mathrm{kg}$ bw). Glucose was measured in samples collected from the tail vein at specified time points. Values are means \pm SE. A) GTT $1 \mathrm{~d}$ after last GH injection. B) GTT 1 mo after last GH injection.

significantly different either from untreated dwarfs or untreated controls (Fig. 6).

\section{DISCUSSION}

In this study we investigated separately the effects of $\mathrm{GH}$ and T4 on longevity in Ames dwarf mice, which are characterized by deficiency of these hormones. We have consistently observed that Ames dwarf mice live longer than their WT controls, but it is still controversial as to whether GH deficiency is the cause of extended longevity in these animals (27). Indeed, the concomitant lack of GH, TSH, and PRL does raise the possibility that hormonal imbalances other than, or in conjunction with, GH deficiency could be important mediators of life span regulation in these animals. The extended longevity of mice that lack the GH receptor/GH binding protein (GHRKO mice), which dis-

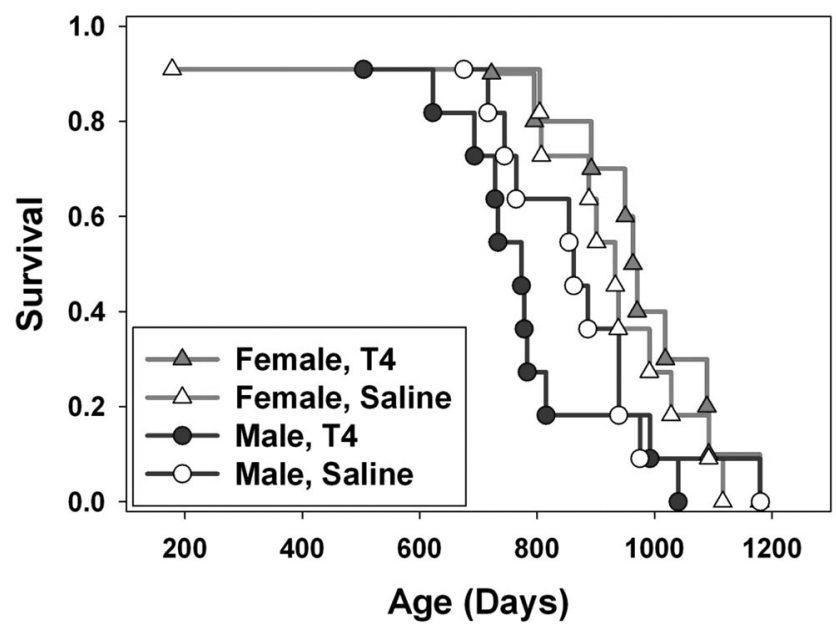

Figure 4. Kaplan-Meier survival plot of male and female Ames dwarf mice treated with T4 or saline $(n=10-11)$. All mice were treated for $6 \mathrm{wk}$ at the age of $2-8 \mathrm{wk}$. rupted GH signaling with apparently normal TSH and increased or normal PRL levels $(5,6)$ suggests that altered GH/IGF levels may be a major factor in the longevity of Ames and Snell dwarf mice. The longevity of PAPP-A-knockout mice, which carry a deletion of a protease that cleaves IGF-1 binding proteins and thus could modulate levels of IGF-1 in multiple tissues, also provides indirect support for a conclusion that diminished GH and/or IGF-1 signals play a major role in the longevity of Ames dwarf mice (28).

We have previously reported that skin-derived cells from Ames, Snell, and GHRKO mice retain resistance to multiple forms of lethal stress through many rounds of in vitro mitosis and cellular proliferation, consistent with epigenetic control mechanisms induced in vivo and maintained in extended culture (22-24). The stress resistance is not present in cells taken from newborn Snell dwarf mice, but arises in the first few months of postnatal life, presumably as a response to differences between dwarf and control mice in circulating hormone levels during early postnatal life (23). Cell lines derived from mice $4-5 \mathrm{~d}$ of age show no genotypic effect on resistance to UV irradiation or cadmium toxicity and only a small difference in $\mathrm{H}_{2} \mathrm{O}_{2}$ resistance, but cells derived from young adult dwarf mice (3-4 mo old) were significantly more resistant to each of these stressors compared to cells from control mice. Snell dwarf and control mice are the same size at birth, reflecting exposure to their shared intrauterine environment, but show different growth trajectories in the first few weeks after birth as they become dependent on their own intrinsic, and distinct, hormonal levels.

Our new data are also consistent with the idea that both longevity and patterns of cellular stress resistance can be influenced by GH and/or IGF-1 signals in the first 2 mo of life. We subjected GH-deficient Ames dwarf mice to GH during early postnatal development, a period during which $\mathrm{GH}$ is critical for growth and for development of physiological organs. Since the average 
A

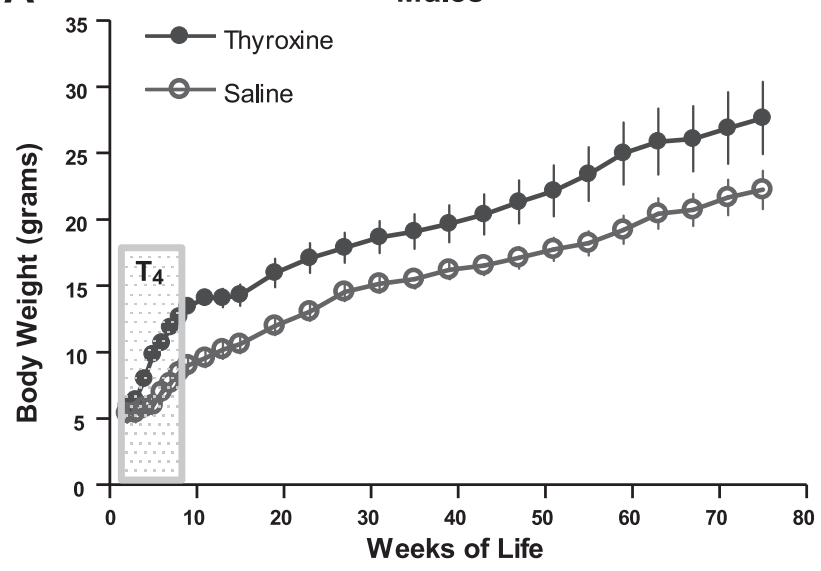

B

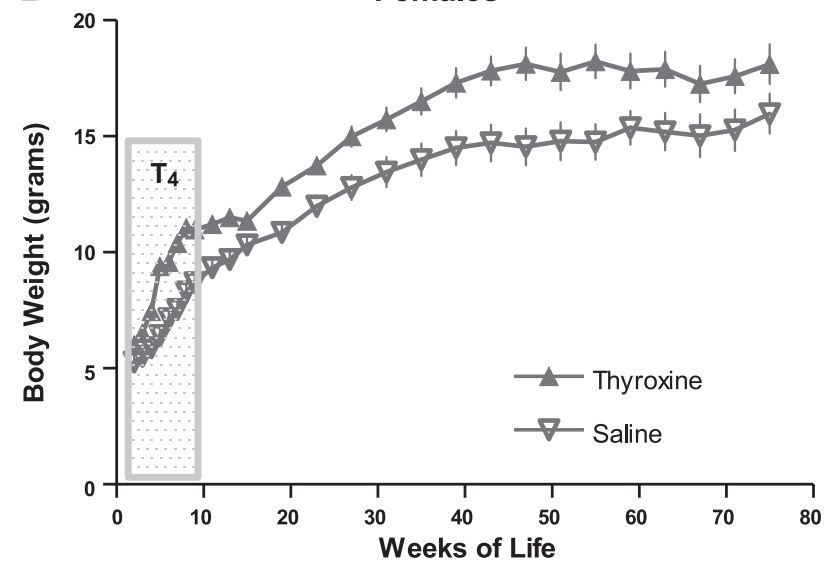

Figure 5. Body weight of male and female Ames dwarf mice subjected to 6 wk of treatment with T4 or saline $(n=10-11)$ during the period indicated on the graph. Time points represent means \pm sE.

life span of $\mathrm{df} / \mathrm{df}$ mice is $\sim 32 \mathrm{mo}$, the $6 \mathrm{wk}$ of treatment represents $<5 \%$ of the expected life span. The weight trajectory of $2 \times / d$ GH-injected dwarf mice was intermediate between that of untreated dwarfs and untreated controls, suggesting that the levels of $\mathrm{GH}$ and IGF-1 produced in these mice did not fully reconstitute the hormonal levels needed for normal growth regardless of increased dosage in $2 \times / \mathrm{d}$-treated mice. In addition, in our previous study using the same protocol, we have shown that $6 \mu \mathrm{g} / \mathrm{g}$ bw/d dosage of GH does elevate circulating IGF-1 but does not normalize it in $\mathrm{df} / \mathrm{df}$ mice (21). Nonetheless, providing GH by $2 \times / \mathrm{d}$ injection during this period shortened the life span of $\mathrm{df} / \mathrm{df}$ mice to match that of WT animals. This intriguing finding strongly suggests that deficiency of GH in $\mathrm{df} / \mathrm{df}$ mice during development is important for their exceptional longevity and that diminished levels of GH signal during early development are critical to the longevity of these animals. Notably, thyroxine supple- mentation administered during the same postnatal period had no effect on life span.

As expected, body weight significantly increased in bGH-treated df/df mice. The lack of complete normalization of body weight in these animals suggests that the animals were not exposed to potentially harmful overdoses of GH. It is possible that more frequent injections or higher doses of GH might allow df/df mice to attain a growth rate characteristic of control mice, although our data do not rule out the idea that normal growth trajectories might require normal levels of both $\mathrm{GH}$ and thyroid hormones. It was shown in pervious experiments that GH treatment suppresses insulin sensitivity and negatively alters insulin signaling in $\mathrm{df} / \mathrm{df}$ mice (21). In the current study, we showed that GH treatment causes glucose intolerance in $\mathrm{df} / \mathrm{df}$ mice, but that this effect seems to be transient and partly reversible within 4-6 wk after discontinuation of the GH injection regimen. Similar alterations in glucose tolerance

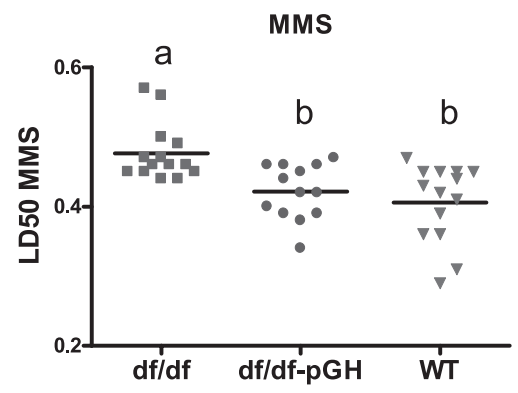

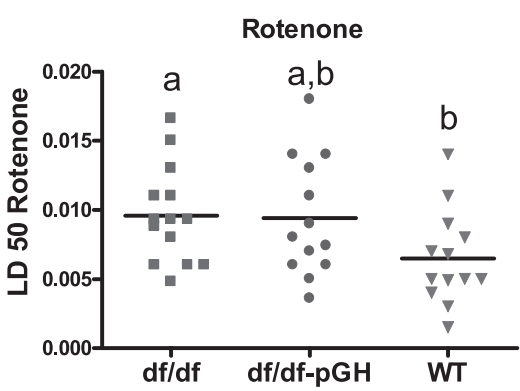

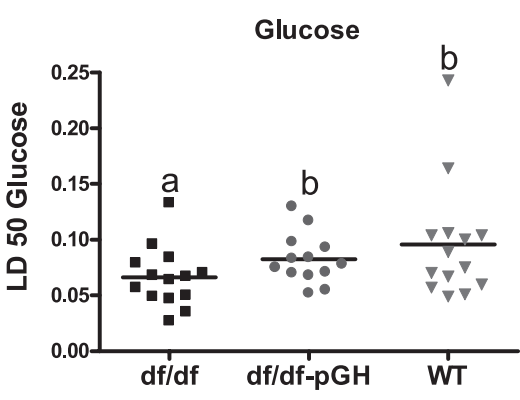

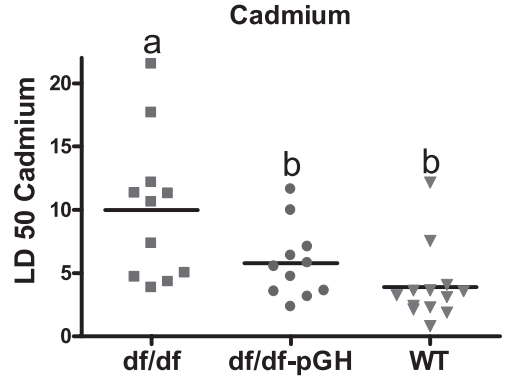

Figure 6. Stress resistance in skinderived fibroblasts from dwarf mice treated with pGH, untreated WT controls, and df/df male mice. Symbols represent individual mice of the indicated genotype; horizontal rule indicates mean value in each case; $n=11-4$. $^{a, b}$ Values that do not share a superscript letter are statistically significant $(P<0.05)$. 
were observed when healthy elderly humans were treated with human recombinant GH (hrGH) (8).

As noted, treating Ames dwarf mice with thyroxine, another hormone dramatically reduced in $\mathrm{df} / \mathrm{df}$ mice, did not alter the longevity of either males or females, although it significantly increased body weight in both genders.

Several studies $(22,24,29,30)$ have suggested that fibroblasts from long-lived species of mammals are resistant to many kinds of stress in vitro, though there are exceptions to this pattern, too. It is not yet known whether the cellular mechanisms that lead to stress resistance in cells from long-lived species are similar to those that lead to stress resistance in cells from Snell, Ames, and GHRKO mice. Our current data show that GH treatment sufficient to restore normal (i.e., reduced) life span in Ames dwarf mice also led to a reversal of the resistance of skin-derived cells to cadmium, paraquat, MMS, and low glucose, producing a set of cellular traits normally seen in cells from WT mice. Moreover, this decline in stress resistance could be demonstrated, in vitro, long after the cessation of exposure to different levels of $\mathrm{GH}$ in vivo, in that the cells from dwarf and GH-treated dwarf mice had been expanded for several weeks in parallel and under identical culture conditions prior to stress testing. Our results suggest that cellular resistance to damage caused by endogenous or environmental stresses could contribute to the longevity of $\mathrm{df} / \mathrm{df}$ mice, although this model depends on the untested assumption that other cell types in these mice also exhibit some of the stress resistance properties documented in skin-derived cultured fibroblasts.

Our present results were somewhat unexpected, because Vergara et al. (31) had previously seen no effect of early life GH treatment on longevity of Snell dwarf mice. Our protocol differed from that of Vergara et al. (31) in a number of potentially influential details. For example, in the Vergara study with Snell dwarfs, GH was administered only $1 \times / d$. Furthermore, the dosages were administered on a per-animal rather than per-unit body weight basis, and thus were effectively declining, from $\sim 8$ to $\sim 3-4 \mu \mathrm{g} / \mathrm{g}$, as the animals grew during the study. Lastly, in the Vergara protocol, GH injections were started at the age of $4 \mathrm{wk}$ (rather than at $2 \mathrm{wk}$ as in the current experiments) and continued up to $15 \mathrm{wk}$ of age. The earlier starting age, adjustments of dose to body weight, and higher frequency of injections in the current protocol may well have accounted for the positive result seen in our study but not in the prior work on aging rate and eventual longevity of Snell dwarf mice. The use of $2 \times / \mathrm{d}$ injections may be especially critical for studies of male mice. It is known that in males $\mathrm{GH}$ is released in a pulsatile fashion into the circulation, and thus injecting mice $2 \times / \mathrm{d}$ may more closely approximate the physiological pattern of $\mathrm{GH}$ release. Differences in background genes may also complicate comparison of the two studies; the Ames control stock differs in many ways from the $(\mathrm{DW} / \mathrm{J} \mathrm{x}$ $\mathrm{C} 3 \mathrm{H} / \mathrm{HeJ}$ )F1 mice used by Vergara et al. (31), and has a substantially shorter life expectancy. Clarification of these ideas would require additional experiments comparing a range of hormonal interventions on several background stocks.

Lifelong exposure to T4 (a protocol we did not explore in the current study) led to partial reduction of the life span of Snell dwarf mice in the Vergara et al. (31) experiments. In contrast, short-term (6 wk) exposure to T4 in our experiments had no significant effect on longevity. It seems plausible that long-term and short-term T4 treatment could well have different effects on health and life span; documentation that the lifelong protocol avoided hyperthyroid toxicity would help to clarify the basis for the effects seen. In any case, our results imply that transient, early life exposure to $\mathrm{GH}$ is more potent than similar treatment with $\mathrm{T} 4 \mathrm{in}$ its effect on longevity in the Ames dwarf mice.

In summary, the present results indicate that transient GH treatment early in life can shorten longevity and decrease cellular stress resistance in Ames dwarf mice. The same treatment was previously shown to be detrimental for insulin signaling in $\mathrm{df} / \mathrm{df}$ mice. We also found that combining identical $2 \times / \mathrm{d} \mathrm{GH}$ treatment with parallel $\mathrm{T} 4$ treatment does not normalize the growth of Ames dwarf mice (20, 21). More work will be needed to confirm these findings on other backgrounds and for other dwarfing alleles to identify the critical "time window" for the observed effects of $\mathrm{GH}$, and to elucidate the mechanism of GH actions on aging and longevity. Our data strongly imply, however, that the levels of GH and/or IGF-1 early in adult life could be a key determinant of longevity and aging rate, and that normal levels of GH signaling during this time reduce mouse life span, presumably by a long-lasting effect on risks of multiple forms of lethal, late-life illness.

Supported by The Ellison Medical Foundation, National Institute on Aging grants AG031736, AG019899, and AG023122.

\section{REFERENCES}

1. Tatar, M., Bartke, A., and Antebi, A. (2003) The endocrine regulation of aging by insulin-like signals. Science 299, 1346-1351

2. Bartke, A., Wright, J. C., Mattison, J. A., Ingram, D. K., Miller, R. A., and Roth, G. S. (2001) Extending the lifespan of long-lived mice. Nature 414, 412

3. Bonkowski, M. S., Dominici, F. P., Arum, O., Rocha, J. S., Al Regaiey, K. A., Westbrook, R., Spong, A., Panici, J., Masternak, M. M., Kopchick, J. J., and Bartke, A. (2009) Disruption of growth hormone receptor prevents calorie restriction from improving insulin action and longevity. PLoS One 4, e4567

4. Brown-Borg, H. M., Borg, K. E., Meliska, C. J., and Bartke, A. (1996) Dwarf mice and the ageing process. Nature 384, 33

5. Coschigano, K. T., Clemmons, D., Bellush, L. L., and Kopchick, J. J. (2000) Assessment of growth parameters and life span of GHR/BP gene-disrupted mice. Endocrinology 141, 2608-2613

6. Coschigano, K. T., Holland, A. N., Riders, M. E., List, E. O., Flyvbjerg, A., and Kopchick, J. J. (2003) Deletion, but not antagonism, of the mouse growth hormone receptor results in severely decreased body weights, insulin, and insulin-like growth factor I levels and increased life span. Endocrinology 144, 3799-3810

7. Rudman, D., Feller, A. G., Nagraj, H. S., Gergans, G. A., Lalitha, P. Y., Goldberg, A. F., Schlenker, R. A., Cohn, L., Rudman, I. W., 
and Mattson, D. E. (1990) Effects of human growth hormone in men over 60 years old. N. Engl. J. Med. 323, 1-6

8. Blackman, M. R., Sorkin, J. D., Munzer, T., Bellantoni, M. F., Busby-Whitehead, J., Stevens, T. E., Jayme, J., O'Connor, K. G., Christmas, C., Tobin, J. D., Stewart, K. J., Cottrell, E., St. Clair, C., Pabst, K. M., and Harman, S. M. (2002) Growth hormone and sex steroid administration in healthy aged women and men: a randomized controlled trial. JAMA 288, 2282-2292

9. Lange, K. H., Andersen, J. L., Beyer, N., Isaksson, F., Larsson, B., Rasmussen, M. H., Juul, A., Bulow, J., and Kjaer, M. (2002) GH administration changes myosin heavy chain isoforms in skeletal muscle but does not augment muscle strength or hypertrophy, either alone or combined with resistance exercise training in healthy elderly men. J. Clin. Endocrinol. Metab 87, 513-523

10. Papadakis, M. A., Hamon, G., Stotts, N., Tierney, M. J., Martin, S. E., Scheuenstuhl, H., and Hunt, T. K. (1996) Effect of growth hormone replacement on wound healing in healthy older men. Wound Repair Regen. 4, 421-425

11. Liu, H., Bravata, D. M., Olkin, I., Nayak, S., Roberts, B., Garber, A. M., and Hoffman, A. R. (2007) Systematic review: the safety and efficacy of growth hormone in the healthy elderly. Ann. Intern. Med. 146, 104-115

12. Bartke, A. (1965) Influence of luteotrophin on fertility of dwarf mice. J. Reprod. Fertil. 10, 93-103

13. Masternak, M. M., Al-Regaiey, K., Bonkowski, M. S., Panici, J., Sun, L., Wang, J., Przybylski, G. K., and Bartke, A. (2004) Divergent effects of caloric restriction on gene expression in normal and long-lived mice. J. Gerontol. A Biol. Sci. Med. Sci. 59, 784-788

14. Sornson, M. W., Wu, W., Dasen, J. S., Flynn, S. E., Norman, D. J., O’Connell, S. M., Gukovsky, I., Carriere, C., Ryan, A. K., Miller, A. P., Zuo, L., Gleiberman, A. S., Andersen, B., Beamer, W. G., and Rosenfeld, M. G. (1996) Pituitary lineage determination by the Prophet of Pit-1 homeodomain factor defective in Ames dwarfism. Nature 384, 327-333

15. Kinney, B. A., Meliska, C. J., Steger, R. W., and Bartke, A. (2001) Evidence that Ames dwarf mice age differently from their normal siblings in behavioral and learning and memory parameters. Horm. Behav. 39, 277-284

16. Csiszar, A., Labinskyy, N., Perez, V., Recchia, F. A., Podlutsky, A., Mukhopadhyay, P., Losonczy, G., Pacher, P., Austad, S. N., Bartke, A., and Ungvari, Z. (2008) Endothelial function and vascular oxidative stress in long-lived GH/IGF-deficient Ames dwarf mice. Am. J. Physiol. Heart Circ. Physiol. 295, H1882-H1894

17. Ikeno, Y., Bronson, R. T., Hubbard, G. B., Lee, S., and Bartke, A. (2003) Delayed occurrence of fatal neoplastic diseases in Ames dwarf mice: correlation to extended longevity. J. Gerontol. A Biol. Sci. Med. Sci. 58, 291-296

18. Dominici, F. P., Hauck, S., Argentino, D. P., Bartke, A., and Turyn, D. (2002) Increased insulin sensitivity and upregulation of insulin receptor, insulin receptor substrate (IRS)-1 and IRS-2 in liver of Ames dwarf mice. J. Endocrinol. 173, 81-94

19. Masternak, M. M., Panici, J. A., Bonkowski, M. S., Hughes, L. F., and Bartke, A. (2009) Insulin sensitivity as a key mediator of growth hormone actions on longevity. J. Gerontol. A Biol. Sci. Med. Sci. 64, 516-521

20. Louis, A., Bartke, A., and Masternak, M. M. (2010) Effects of growth hormone and thyroxine replacement therapy on insulin signaling in Ames dwarf mice. J. Gerontol. A Biol. Sci. Med. Sci. 65, 344-352

21. Masternak, M. M., Panici, J. A., Wang, F., Wang, Z., and Spong, A. (2010) The effects of growth hormone $(\mathrm{GH})$ treatment on $\mathrm{GH}$ and insulin/IGF-1 signaling in long-lived Ames dwarf mice. J. Gerontol. A Biol. Sci. Med. Sci. 65, 24-30

22. Harper, J. M., Salmon, A. B., Leiser, S. F., Galecki, A. T., and Miller, R. A. (2007) Skin-derived fibroblasts from long-lived species are resistant to some, but not all, lethal stresses and to the mitochondrial inhibitor rotenone. Aging Cell 6, 1-13

23. Murakami, S., Salmon, A., and Miller, R. A. (2003) Multiplex stress resistance in cells from long-lived dwarf mice. FASEB J. 17, 1565-1566

24. Salmon, A. B., Murakami, S., Bartke, A., Kopchick, J., Yasumura, K., and Miller, R. A. (2005) Fibroblast cell lines from young adult mice of long-lived mutant strains are resistant to multiple forms of stress. Am. J. Physiol Endocrinol. Metab 289, E23-E29

25. Leiser, S. F., Salmon, A. B., and Miller, R. A. (2006) Correlated resistance to glucose deprivation and cytotoxic agents in fibroblast cell lines from long-lived pituitary dwarf mice. Mech. Ageing Dev. 127, 821-829

26. Leiser, S. F., and Miller, R. A. (2010) Nrf2 signaling, a mechanism for cellular stress resistance in long-lived mice. Mol. Cell. Biol. 30, 871-884

27. Sonntag, W. E., Carter, C. S., Ikeno, Y., Ekenstedt, K., Carlson, C. S., Loeser, R. F., Chakrabarty, S., Lee, S., Bennett, C., Ingram, R., Moore, T., and Ramsey, M. (2005) Adult-onset growth hormone and insulin-like growth factor I deficiency reduces neoplastic disease, modifies age-related pathology, and increases life span. Endocrinology 146, 2920-2932

28. Conover, C. A., and Bale, L. K. (2007) Loss of pregnancyassociated plasma protein A extends lifespan in mice. Aging Cell 6, 727-729

29. Kapahi, P., Boulton, M. E., and Kirkwood, T. B. (1999) Positive correlation between mammalian life span and cellular resistance to stress. Free Radic. Biol. Med. 26, 495-500

30. Salmon, A. B., Sadighi Akha, A. A., Buffenstein, R., and Miller, R. A. (2008) Fibroblasts from naked mole-rats are resistant to multiple forms of cell injury, but sensitive to peroxide, ultraviolet light, and endoplasmic reticulum stress. J. Gerontol. A Biol. Sci. Med. Sci. 63, 232-241

31. Vergara, M., Smith-Wheelock, M., Harper, J. M., Sigler, R., and Miller, R. A. (2004) Hormone-treated snell dwarf mice regain fertility but remain long lived and disease resistant. J. Gerontol. A Biol. Sci. Med. Sci. 59, 1244-1250

Received for publication April 24, 2010 Accepted for publication August 5, 2010. 